\title{
¿PARTIR DEL DASEIN O PARTIR DEL JUDAÍSMO? EL JUDAÍSMO COMO CATEGORÍA FILOSÓFICA EN LEVINAS Y UNA POSIBLE ACTUALIZACIÓN DEL PROBLEMA
}

\author{
Diego Fonti y Francisco Guevara* \\ doi: 10.11144/Javeriana.uph35-71.pdj1
}

\begin{abstract}
RESUMEN
La obra de Levinas se ubica explícitamente en la herencia fenomenológica. Sin embargo, en repetidas ocasiones recupera nociones provenientes de la tradición religiosa, particularmente judía, al punto de afirmar que el judaísmo es una "categoría del ser". Este trabajo analiza el rol del judaísmo como categoría a partir de la reconstrucción del sentido de esa noción en los autores más influyentes en la filosofía levinasiana. Finalmente, se muestra el rol y significado que esta estructura categorial asume en Levinas a partir de cuatro núcleos: la exposición de la alteridad como separación y gloria; la relación de responsabilidad como elección y sustitución; la comprensión de la temporalidad como creación y redención; y la exposición del lenguaje a partir del profetismo.
\end{abstract}

Palabras clave: Levinas; categoría; Dasein; judaísmo; responsabilidad

\footnotetext{
Universidad Católica de Córdoba, Argentina / CONICET - Instituto Domingo Savio, Universidad Católica de Córdoba, Argentina / CONICET.

Correo electrónico: diegofonti@gmail.com - pguevara61@gmail.com

Para citar este artículo: Fonti, D., \& Guevara, F. (2018). ¿Partir del Dasein o partir del judaísmo? El judaísmo como categoría filosófica en Levinas y una posible actualización del problema. Universitas Philosophica, 35(71), pp. 259-293. ISSN 0120-5323, ISSN en línea 2346-2426. doi: 10.11144/ Javeriana.uph35-71.pdj1
} 


\title{
JUDAISM AS A PHILOSOPHICAL CATEGORY IN LEVINAS: AN UPDATE OF THE PROBLEM
}

\begin{abstract}
Levinas's work is explicitly placed within the heritage of the Phenomenological school. Nevertheless, he repeatedly uses notions drawn from the religious tradition, especially Jewish, up to the point of stating that Judaism is a "category of being". This paper analyses the role of Judaism as a category, beginning with a reconstruction of this notion in the most influential authors within Levinas's philosophy. Finally, the role and meaning that this categorial structure take on in Levinas will be shown, through the examination of four main components: the exposition of alterity as separation and glory; the relationship of responsibility as election and substitution; the understanding of temporality as creation and redemption; and the prophetical understanding of language.
\end{abstract}

Keywords: Levinas; category; Dasein; Judaism; responsibility 
LA FILOSOfía DE Levinas ha sido recibida de modo fecundo tanto por pensadores y pensadoras con expresos compromisos religiosos como sin ellos. Pero la filiación religiosa de muchos de los términos y contenidos empleados por el filósofo es inocultable. Es clara la influencia de Rosenzweig y su exposición de nociones derivadas del judaísmo, así como el peso de esta influencia en la decisión levinasiana de tomar nociones que no provenían de la tradición filosófica sino de la religiosa. Ante dicha filiación e influencia, cabe preguntar: ¿qué opciones metodológicas llevan a Levinas a ir más allá de lo que su propia formación fenomenológica permite? ¿Es un desborde de la fenomenología o una consecuencia derivada de sus propios postulados? Posiblemente una frase de Bernhard Casper permita un punto de partida para la respuesta: "De otro modo que Husserl y más allá de Heidegger” (Casper, 2008, p. 257). Sucede que Levinas entiende que en la experiencia del Otro se accede a un "fenómeno" que desfasa la correlación intencional y la donación de sentido, al tiempo que se excede el análisis ontológico mediante su reubicación en una experiencia que él considera más fundamental que lo que puede abrir la ontología (Levinas, 1951). En este trabajo se seguirá esa hipótesis, sosteniendo que la tradición judía -tanto en sus textos como en sus experiencias históricas- provee a Levinas los términos, y con ellos un particular mundo de significados, que posibilitan una hermenéutica de dicha experiencia. Se trata del "horizonte de sentido", la idea fundamental que recibe Levinas de Husserl (Levinas, 2001, p. 151). Ese horizonte no significa una teología, fides quaerens intellectum, tampoco la apología de una religión particular, sino un movimiento invertido que no trata de apelar a conceptos filosóficos para expresar racionalmente lo que se cree, sino que se vuelve al horizonte de significación religioso en busca de significantes capaces de expresar aquello que se muestra en el fenómeno, excediéndolo.

La influencia de Rosenzweig no solo se evidencia en la referencia a La estrella de la redención al inicio de Totalidad e infinito, donde afirma que ese libro está "demasiado presente [...] como para ser citado" (Levinas, 1995, p. 54). También son trazables antecedentes previos en estudios y anotaciones de Levinas, muchas de ellas hasta hace poco inéditas, así como explícitamente en estudios posteriores. Pocas expresiones son tan claras para echar luz tanto sobre Rosenzweig 
como sobre su propia obra, como cuando Levinas afirma que para Rosenzweig el judaísmo "no es ya solamente una enseñanza, cuyas tesis serían verdaderas o falsas, la existencia judía en si misma es un acontecimiento esencial del ser, la existencia judia es una categoría del ser" (Levinas, 2005b, p. 203). Esta afirmación escrita por Levinas en su madurez se ha de leer en relación con las siguientes afirmaciones escritas por Levinas en ese período de profunda reflexión que se dio durante su cautiverio en el Stalag: "Partir del Dasein o partir del 'judaísmo"” "El <judaísmo> como categoría” (Levinas, 2013, p. 42). Impactado por los textos de Leon Bloy, que usa las "categorías del catolicismo" para alojar en ellas "todo lo que es humano", Levinas considera que es "el mismo trabajo a emprender por el judaísmo" (Levinas, 2013, p. 151).

¿Son esos fragmentos meras anotaciones de borrador, sin mayor peso a la luz de la envergadura de toda su obra? ¿Son un exceso de retórica debida a ese momento de su historia? ¿Hay que desecharlos -junto a su carga personal contextual- para concentrarnos filosóficamente en aquello que el fenómeno nos dona, sin acudir a otro presupuesto? ¿Debemos concederle a Levinas que recurra a su propia tradición, como una concesión quizás excesiva pero necesaria en una era de pluralismo? ¿O acaso tienen esos fragmentos un valor filosófico, o sea comprensible para quien aborde el fenómeno en cuestión, con independencia de la tradición de donde surgen? Estas preguntas indican la necesidad no solo de ubicar el problema de lo religioso en la filosofía de Levinas, sino de plantear esta relación como heredera de una larga tradición, con tensiones y conflictos. No se trata de la alternativa de judaísmo o (aut aut) filosofía. Se trata de abordar la tarea filosófica desde una ubicación en la vida, que da al mundo de la vida una historicidad y concreción definidas, y lleva a pensar los existenciales que estructuran al Dasein desde una ubicación espacio-temporal concreta, a nivel de vivencias definidas pero con características universales. De allí la intuición del joven Levinas, prisionero de guerra en una época de exterminio, expresada en ambas afirmaciones sobre el judaísmo y su rol filosófico, que hallan eco en toda su obra.

Tomar filosóficamente en serio estas afirmaciones, y no solo como una expresión retórica o ilustrativa, conduce obligatoriamente a la pregunta sobre su sentido, su rol en una filosofía que no sea exclusiva para "creyentes", y su función en una sociedad marcada por la modernidad secularizada. Para ello, este trabajo abordará la tarea de investigar cuál es el sentido de "categoría" aludido. Con ese 
objetivo, se indagarán sus principales comprensiones, aristotélica y kantiana, el uso fenomenológico y su contraposición a los existenciales en Heidegger. Todo esto como preparación para una revisión de los términos con que Levinas permite comprender la existencia humana en sentido universal a partir de su ser-judío y los sentidos que esta condición abre. Las palabras de Levinas (2005b) sobre esta tarea parecen convenientes: "filosofar es avanzar hacia el puerto donde se ve la luz que ilumina significaciones primeras, pero que ya tienen un pasado" (p. 149).

\section{La categoría y sus hitos}

EN LA HISTORIA DEL PENSAMIENTO FILOSÓfico existen conceptos imprescindibles no solo para la elaboración de las diversas filosofías, sino también para entender el tipo mismo de filosofía que habilitó cada modo histórico de comprensión de esos conceptos. Categoría es uno de ellos. En su origen griego el término significaba acusación, apóstrofe dirigido a alguien de modo súbito, pero también lo que se afirmaba sobre algo. En los textos primeros de la filosofía no se encuentra el término, sino a partir del momento de reflexión crítica o vuelta del pensamiento filosófico sobre sí, cuando este busca ver cómo se relaciona con el ser y con entes, y cómo realiza su propio modo de definición y clasificación. Por eso, para muchos "la historia del concepto de categoría es al mismo tiempo una historia de autointerpretación filosófica" (Baumgartner et al., 1976, p. 712). Aristóteles y Kant inician las dos comprensiones más influyentes de las categorías. A partir de su comprensión metafísica del mundo y el vínculo entre realidad, intelecto y lenguaje, Aristóteles expone las categorías en clave ontológica y lógica: categorías son los modos en que la inteligencia se relaciona con la realidad con que se encuentra. La relación de lógica y ontología es a la vez de independencia y subrogación; las normas del lenguaje deben ser respetadas y ellas mismas permiten evitar confusiones, siempre que, por otro lado, su afirmación concuerde con la realidad. Por su parte, Kant expone las categorías en clave trascendental y lógica, por lo que la dependencia en este caso es respecto de la estructura del sujeto trascendental que de hecho objetiva al mundo. Así, reconstruyendo el proceso de constitución de sus objetos pueden deducirse las categorías que el sujeto porta consigo y son efectivas a la hora de llevar a cabo esta constitución. 
Esta doble tradición tiene efectos a lo largo de la historia de la filosofía, y casi la totalidad de quienes tomaron la noción utilizaron de un modo u otro el campo semántico originado en ambos pensadores. Teniendo en cuenta el objetivo de este trabajo, vale retomar el análisis del concepto en el siglo XX, cuando la fenomenología husserliana, con su intento de ir a las cosas mismas, resignifica a la categoría como condición de unidad, sea del fenómeno, sea de toda experiencia en absoluto, ubicando finalmente a las categorías en un rol secundario respecto del rol constitutivo de la conciencia trascendental. Frente a esta centralidad de lo teórico y del sujeto, Heidegger propone su propio análisis, que al centrarse en el ser del Dasein -el existente humano en cuyo ser le va su propio ser- se ve forzado a dejar de lado las categorías propias del resto de las entidades y establecer su análisis a partir de existenciales.

\subsection{ONTO-LÓGICA O LÓGICA TRASCENDENTAL}

LAS PRIMERAS ELABORACIONES CATEGORIALES en sentido explícito posiblemente sean las parejas contrapuestas de los pitagóricos, donde todavía no aparece claramente la cuestión de universal y particulares, conceptos y realidad. Lo universal en lo múltiple aparece a partir de la herencia socrática en los diálogos platónicos: solo al separar lo general como principio esencial de los particulares se logra lo propio de la categoría. La categoría tiene siempre que ver con lo originario y el modo en que más o menos una entidad participa del orden pleno del ser (Krämer, 1967, p. 235). Pero es en Aristóteles donde las categorías parecen estar en condición de separar lo particular de sus accidentes, y dentro de lo particular, lo propio de la unicidad de su especie. Krämer (1967, p. 168) afirma que a pesar del "cambio de peso" de la pirámide platónica a los órdenes "más bajos" del ser en Aristóteles, y la inversión de la secuencia del ser (como en Categorias, 2b-3a) no se afecta la idea del vínculo ontológico-lógico. Y aunque el uso del término categoría es poco frecuente en Aristóteles, tuvo una importancia y efectos notables en la historia del pensamiento y el modo de estructurar la comprensión de la realidad.

La primera obra aristotélica que presenta un elenco de las categorías es Tópicos, y se reformula en Categorias, pero es en las notas denominadas Metafisica donde se desarrolla el sentido de ser que corresponde a cada una. En el sentido 
que Aristóteles da al término en sus obras, categoría ya no alude a una "acusación" sino a un "predicado" (Categorías, cap. XIII). Así, el sentido inmediato en Aristóteles es "el hecho de decir una cosa de la otra" (légein ti katá tinos), bajo formas o especies posibles de predicados. Aristóteles trabaja en dos registros estrechamente vinculados pero diversos, el lógico y el ontológico. Esto le permite separar el concepto de esencia de otras afirmaciones universales de los predicables. Aunque las categorías permiten entender los principios metafísicos de lo real, ellas son en última instancia siempre predicaciones que pueden darse a partir del encuentro con la realidad y la comprensión de sus principios. Así separa lo que se dice que un individuo porta en sí como su fundamento, de lo que se afirma sobre eso. En la comprensión de la esencia se distingue el momento del principio del ser del momento del concepto general y abstracto. Por eso Aristóteles diferencia entre las categorías de lo que está en lo real de otras que son construidas por los individuos para comprender lo real. Finalmente también se diferencian estas categorías de aquellas que son predicados de la sustancia individual real, cuando lo que se afirma no es de la esencia que está en la base ni está contenido por ella, o sea los accidentes. Al tomar un caso particular, Aristóteles enumera las diez categorías (Cat. 1b25-2a10). Todo lo que es, de alguna manera, es expresable por esas categorías. Por lo tanto, las categorías no son caracteres que configuran al ente, sino modos de afirmaciones referenciales de diversos modos de ser. Lo lingüístico y lo ontológico están coimplicados. Las categorías no constituyen lo que hay sino que permiten describir modos de ser y evitar su confusión. Fuera de la serie se sitúan los entes individuales, que en la predicación solo pueden funcionar como sujetos, y que son cognoscibles o definibles nada más que como miembros de su especie ínfima.

La influyente tradición de la noción aristotélica de categorías se proyectó a lo largo de todo el medioevo, incluso en períodos y autores platonizantes. La crítica de la "teología negativa", del nominalismo y de los empirismos al inicio de la modernidad puso en cuestión el valor epistemológico de las categorías como afirmación sustentada de la realidad. Con la excepción de su uso por parte de algunos pensadores católicos, desde inicios de la modernidad las categorías pierden su sentido ontológico y progresivamente son vistas como una síntesis más o menos arbitraria de fenómenos de la realidad (Baumgartner et al., 1976 , pp. 725 y ss.). 
En medio de la crisis epistemológica debida al empirismo, la respuesta y reconstrucción trascendental de Kant las asume resignificándolas de modo radical. Kant afirma que frente a la multiplicidad fenoménica que el sujeto recibe, este produce una síntesis por la imaginación, aunque esa síntesis permanece ciega si no es llevada por el entendimiento a conceptos. Al estudiar cómo el entendimiento opera esa síntesis, Kant deduce su constitución a priori y sus funciones. Denomina a esta estructura lógica trascendental, y la distingue de la lógica formal, porque su tarea es permitir identificar los conceptos de un objeto en general que proveen las funciones lógicas para hacer posibles los juicios. De otro modo, lo múltiple no podría ser "recorrido, acogido y enlazado, para hacer de él un conocimiento" (CRP, A 77). La síntesis pura en general da el concepto de entendimiento. Este produce representaciones por medio de la unidad sintética y juicios por medio de la unidad analítica, y al analizar estas funciones se ven los "conceptos puros del entendimiento que se refieren a priori a objetos de la intuición en general", las categorías (CRP, B 105).

Las categorías son "condiciones de posibilidad de la experiencia", conceptos con que el sujeto trascendental prescribe leyes a priori a todos los fenómenos, permitiendo que haya experiencia y objeto. Las categorías no provienen de la experiencia; al contrario, su aplicación es una condición de posibilidad de la experiencia. Kant estudia las categorías desde el principio fundamental de la capacidad de juzgar, y a partir de su uso indaga, por deducción trascendental, su estructura y la condición de su posibilidad en la relación con los objetos de la experiencia. La experiencia es comprensible y ordenable porque la síntesis empírica de la aprehensión depende de la síntesis trascendental de las categorías. La unidad de esta síntesis no solo somete a los fenómenos a unidad, sino que indirectamente desemboca en la unidad de la apercepción, la conciencia propia que acompaña todo pensamiento (CRP, A 146). Como las intuiciones y los conceptos son heterogéneos, es necesario subsumirlas para que haya conocimiento. Así, las categorías son aplicadas sobre las intuiciones por "esquemas" trascendentales, o sea las condiciones que relacionan objetos y significados (CRP, A 138). Las categorías no valen por sí, sino que solo tienen uso en tanto "entienden" las percepciones y permiten "leerlas". Son a la vez conceptos y condiciones que permiten que haya experiencia y tienen valor objetivo a priori. 
Finalmente, la estructura trascendental de las categorías muestra que se relacionan con lo sensible por medio de la "imaginación productiva", que permite que las categorías reconozcan ordenadamente lo múltiple que aparece bajo la forma de la experiencia (CRP, A 140). Así, el entendimiento es origen de las leyes de la naturaleza. Estas funciones tienen como característica, entonces, las de ser "connaturales" al sujeto trascendental y a la lógica de sus operaciones objetivantes de la experiencia.

Levinas (1994) destaca del análisis kantiano que en la actividad sintética del entendimiento las categorías constituyen lo concreto y cognoscible, pero no la totalidad de la realidad, pues queda fuera lo que excede al conocimiento. Esto es importante porque hay "significados que poseen su propio sentido sin reducirse a la epopeya del ser" (pp. 75-76). En otro texto, luego de analizar el ideal trascendental en la filosofía práctica kantiana, y su rol respecto del conocimiento, Levinas (1994) afirma que no se trata de "ampliar la noción de ser más allá de las cosas, sino de proponer un enjuiciamiento radical” (p. 186). Ambas posiciones, la posibilidad de ir más allá del orden del ser que abre Kant, y la afirmación de que se trata menos de ampliar la noción de ser que de traerla a un juicio radical, son interesantes por dos motivos. Ante todo, obligan a revisar la resignificación de la "categoría" en el uso levinasiano. Pero además permiten entender cómo y por qué los existenciales -que como se expondrá a continuación reemplazan a las categorías en el análisis del Dasein- finalmente también quedan en el ámbito del ser y de la finitud, por lo que no permiten significados vinculados con la trascendencia y el infinito ${ }^{1}$.

1 Un capítulo que excede largamente el límite de este trabajo es la reconstrucción del rol de Kant en las discusiones entre el neokantismo (sobre todo Cassirer) y Heidegger, y la influencia de estas sobre Levinas. La presencia de este último en el encuentro de Davos es un dato relevante, porque allí se debatía, por un lado, la filosofía racionalista y todavía trascendental a pesar de la importancia de lo simbólico y, por otro, la ontología de la existencia auténtica, así como también el liberalismo universalista y racional frente al pathos de una existencia entramada en el mundo de la vida. Ambas posiciones significaron de modo explícito la disputa sobre cómo interpretar a Kant (Gordon, 2010). Sería un significativo trabajo indagar las preocupaciones de Cassirer y Heidegger sobre Kant y sus interpretaciones sobre el rol del terminus ad quem y el terminus a quo respecto de la filosofía de Levinas mismo. Es notable que Levinas también se refiriera expresamente a la herencia kantiana como un núcleo de su filosofía. 


\subsection{CONDICIÓN DE UNIDAD TRASCENDENTAL O EXISTENCLALES}

La fenomenología de Husserl tiene por objetivo fundante ir a las cosas mismas, en el modo en que originariamente se da su fenómeno a la conciencia estructurada de manera intencional. A partir de esta idea y a lo largo de sus variaciones, en Husserl se encuentra una doble acepción de las categorías, como dos facetas de una misma exposición: los conceptos primitivos accesibles por intuición categorial, que permiten unidad y conexión de los fenómenos, y la conciencia trascendental, como protocategoría original del ser. Por ello se desvincula tanto de los supuestos metafísicos de las categorías de la tradición aristotélica, como también de los psicologismos que relativizan las afirmaciones sobre el mundo a cómo está dada la estructura psicológica. Las categorías tampoco son conceptos a priori que porta el sujeto trascendental, sino conceptos fundamentales del conocimiento, y ello es así tanto para las "categorías significativas" que establecen conexiones ideales regulares de fenómenos, como para las "categorías objetivas formales" (Husserl, 1997a, p. 202), que son conceptos correlativos que entienden los modos de relación.

Por un lado, las categorías no corresponden al ámbito de la razón de los sujetos, sino que pertenecen a los objetos de conocimiento y a las condiciones objetivas del conocimiento, sea en la significación, sea en la estructura lógica que expresa lo conocido. Así, las categorías son "conceptos primitivos" que hacen posible la unidad y conexiones regulares ideales en el conocimiento del objeto (Husserl, 1997a, p. 201). Se comprenden a partir del fenómeno y son seres objetivamente indicados, que pueden ser expuestos formalmente por la lógica de las oraciones en el lenguaje. En este sentido dependen del pensamiento, pero no las construye ni porta en sí el pensamiento, sino que hay una intuición específica a la que se accede en la relación noético-noemática con el fenómeno, la intuición categorial (Husserl, 1997b, p. 693). Toda intuición es un acto "impletivo", cumplido, en tanto un contenido del lenguaje se correlaciona con un dato fenoménico. La intuición sensible directa y simple es completada por la intuición categorial, que comprende las conexiones englobantes. El "acto categorial" que se da en la intuición tiene una cualidad, materia intencional y representantes (Husserl, 1997b, p. 720). Independientemente del tipo de aprehensión y de cumplimiento que permitan los fenómenos, las categorías son conceptos a los que accede el 
pensamiento mediante una intuición específica, al identificar conexiones en las variaciones de los fenómenos. En este marco, a nivel lógico, significado y objeto son las categorías fundamentales mientras que, a nivel material, las categorías son los conceptos fundamentales de cada región del conocimiento científico.

Todo el tiempo nuestra conciencia es conciencia de algo: percibe, juzga y realiza otras actividades respecto del estado de cosas con que se encuentra. Levinas resalta que para Husserl dicho estado de cosas revela que entre lo que constituye el ser que se revela a la conciencia no están solo los objetos sino también las categorías. El propio objeto está provisto de una forma categorial (Levinas, 2004a, p. 104). Según Levinas, en la forma categorial en tanto que "ser cópula" hay una indiferencia respecto de la materia aludida. Debido a que la forma categorial no es parte del objeto mismo, Kant la ubicó en la esfera sintética de la conciencia. Para Husserl sí pertenece a los objetos, pero, destaca Levinas (2004a), "la forma categorial no es un predicado real de la cosa, ni resultado de una reflexión sobre la conciencia. Es la estructura ideal del objeto" (p. 106). Es gracias a la intuición categorial o intelectual que constituimos el estado de cosas que comprendemos (Levinas, 2004a, p. 107).

Según Husserl, cuando se realizan las tareas de reducción fenomenológica, se accede a un estrato más fundamental sobre el cual se asienta la acepción anterior: se alcanza la protocategoría originaria del ser como tal, o sea la conciencia trascendental. En Ideas (Husserl, 1992) advierte: "entre la conciencia y la realidad en sentido estricto se abre un verdadero abismo de sentido. Aquí un ser que se matiza o escorza, que nunca se da absolutamente [...], allí, un ser necesario y absoluto" (p. 114). Toda otra categoría tiene un sentido secundario respecto de la conciencia trascendental, fuente originaria de unidad y síntesis. Más acá de las vivencias aisladas, y más allá de la consideración psicologista de la conciencia y sus resultados, se accede a una base que permite comprender

[...] cómo pueden llegar a entrar en la inmanencia de la vida de la conciencia, y en modos de la conciencia, [...] algo así como unidades objetivas estables $y$ permanentes, y en particular cómo tiene lugar esta maravillosa obra de la constitución de objetos idénticos en cada categoría de objetos, es decir, qué aspecto tiene y no puede menos de tener en cada una la vida de conciencia constituyente, en cuanto a las correlativas variantes noéticas $y$ noemáticas del mismo objeto (Husserl, 1996, pp. 97 y ss.). 
Por la reducción trascendental el ego se capta "a sí mismo en su ser propio primordial”, y también a los otros egos trascendentales (Husserl, 1996, p. 219). Este es el origen tanto de la crítica heideggeriana al intelectualismo de Husserl -crítica que es fundamental como punto de partida del pensamiento levinasiano-, como de la propia necesidad de Levinas de superar esa visión monadológica de la relación con los demás.

Frente a cierto intelectualismo o idealismo que persiste en Husserl, Heidegger recupera el suelo del mundo de la vida para sus análisis, ante todo en el período en que busca una "ontología fundamental". En Ser y tiempo sostiene que es un error imponer al Dasein una serie de "categorías" a priori para explicar el modo de su ser (Heidegger, 1997, p. 26). Si el Dasein es el ente a cuyo ser le va su propio ser, y abre el sentido de su ser a partir de sus modos fundamentales de ser, entonces sus "regularidades" no pueden entenderse por alguna noción de categoría como las expuestas anteriormente. El problema de fondo es que esas categorías siempre son articuladas por ontologías que son "ciegas y contrarias" a la finalidad más propia del Dasein, porque no exponen ante todo el sentido del ser (Heidegger, 1997, p. 21). La única base fundamental sólida para exponer ese sentido para el Dasein es su existencia como relación con el ser: "estos caracteres de ser del Dasein se determinan desde la existencialidad, los llamamos existenciales. Se los debe distinguir rigurosamente de las determinaciones de ser del ente que no tiene la forma de ser del Dasein, a las que damos el nombre de categorías" (Heidegger, 1997, p. 53). Según se trate de la ontología que aborda al Dasein -el ente al que en su ser le va su propio ser, o sea los humanos-, o se trate de todos los demás seres que "están ahí", tenemos las dos formas básicas de constitución de términos para exponer sus estructuras: "existenciales y categorías son las dos posibilidades fundamentales de los caracteres del ser" (Heidegger, 1997, p. 54). Para Heidegger, las características fundamentales de lo que es pueden exponerse como categorías o como existenciales. Las categorías remiten al plano óntico, por lo que son consideradas en un lugar secundario respecto de los existenciales que abren el sentido del ser para el Dasein. También abandona el análisis fenomenológico de la subjetividad trascendental, en sentido de Husserl, en pos de una hermenéutica del Dasein.

Los existenciales muestran la estructura de la existencia del Dasein, no entendida como una realidad presente sino como la esencia del ser humano en 
tanto aquel ente que se relaciona siempre de algún modo con su ser. Dasein, ser-ahí, indica la expresión del ser que diferencia al ser humano de otros entes, en tanto aquel tiene su esencia en la existencia, cuya característica fundamental es la apertura al ser mismo. Tanto los existenciales como las categorías son "posibilidades fundamentales" de los caracteres del ser. Las ontologías que abordaron al Dasein desde sistemas categoriales permanecieron "ciegas" a su fundamento y a su tarea esencial. Por eso "si una ontología no entiende esa, su meta más propia y esencial, permanece ciega sobre su propia esencia, confunde su propia esencia” (von Herrmann, 1987, p. 99). La tarea fundamental de la ontología es la pregunta por el sentido del ser como tal, y el lugar por antonomasia de la pregunta es el Dasein, el ente a cuyo ser le va ocuparse del ser. Y las características estructurales del Dasein son los existenciales, como ser-enel-mundo (In-der-Welt-sein), disposición afectiva (Befindlichkeit), comprender (Verstehen), lenguaje comunicativo (Rede), caída (Verfallen), cuidado (Sorge), temporeidad (Zeitlichkeit) e historicidad (Geschichtlichkeit). Se muestran como indicaciones formales y, en este sentido, ontológicas y no ligadas a una entidad o historicidad particular.

Levinas sostiene que una gran enseñanza de Husserl, de la que Heidegger es deudor, es que la especificidad de todo objeto se pone a salvo de falsas interpretaciones -la idea ingenua de existencia, el reductivismo objetivista o subjetivista, etc.- mediante el análisis del pensamiento que respeta el sentido específico de toda manifestación: "cada objeto con un sentido determinado tiene esencialmente un modo propio de ser dado" (Levinas, 2005a, p. 59). Esta afirmación impacta también en Levinas, pues la "categoría" en su relación con el judaísmo accede a un modo propio y diverso, mientras que el "ser" que allí se manifiesta excede la indicación formal posibilitada por la ontología. Finalmente, el "objeto" al que así se accede es un "polo" en torno al cual se gira y permite una síntesis siempre inacabada, punto de partida para el acto y objeto categorial fundado, que permite mostrar lo que significa su realidad para el pensamiento (Levinas, 2005a, pp. 60 y ss.). Pero ese "polo" se revela históricamente y semánticamente situado, horizonte de significación previo a toda formalización ontológica. De allí que sea necesario un trabajo detallado de los sentidos del uso de "categoría del ser" en Levinas, para evitar tanto la "heideggerización" de Levinas como una escisión tan absoluta que desconozca los vínculos de ambos pensadores. 
LEVINAS ROMPE CON LA IDEA DE CATEGORÍA propia de las filosofías de la representación, pues, para él, no es el sujeto quien trae de modo soberano a su conciencia la presencia del objeto. Su formación fenomenológica lo lleva en un principio a la comprensión de la conciencia como intencionalidad, capaz de un tipo de trascendencia y apertura a cada objeto con sus particularidades. Como lo dice en "La ruina de la representación" (Levinas, 2005a), la "nueva ontología" husserliana significa que el ser funda al pensamiento, que por su parte lo constituye (p. 189). Esto muestra que todo sujeto está entramado en una "pasión básica", una "situación", que tendrá una elaboración notable con Heidegger (Levinas, 2005a, p. 190). Pocos párrafos después pondrá como elemento esencial de esa situación al "mundo cultural [...] cuyo ser mismo consiste en conferir un sentido". Este mundo cultural "sostiene, en los análisis fenomenológicos, todo lo que, en las cosas y en las nociones, simplemente parece ser el contenido y lo dado" (p. 193). Esta breve oración contiene una idea central: la situación histórica encuentra en el mundo cultural un modo de conferir sentido que reúne, categoriza, lo que se manifiesta en los análisis fenomenológicos. Aunque sea reductivo entender al judaísmo solo como "mundo cultural", es un buen punto de partida para comprender el modo en que Levinas resignifica el término. Y tiene relevancia porque Levinas (2004b) se encargará no solo de mostrar cómo funciona la particularidad de la "categoría" del judaísmo, sino también que la particularidad, la excepción, tiene en este caso el extraño rol de reunión universal: el destino judío ha sido el lugar donde se jugó el destino humano: "la ecuación reversible: judío = hombre; hombre = judío, marcará la renovación judía en Occidente" (p. 218). La experiencia del judaísmo es un modelo de relación que le permite comprender cómo, en el encuentro con el Otro, la intencionalidad queda desfasada; es un modelo categorial que elabora una síntesis inacabada por la propia materia en cuestión, su contenido y representante.

La experiencia de la guerra y la posterior reflexión sobre la muerte y aniquilación de judíos hacen converger sus posiciones filosóficas con la identificación de las mismas a partir de su propia tradición. Por ejemplo, en La spiritualité juive chez le prisonnier israélite (Levinas, 1945/2013) para describir su situación emplea las categorías que diez años antes utilizaba en De l'évasion para referirse al 
encadenamiento al ser: "el israelita se sabía en un mundo duro, sin ternura, sin paternidad. Él existía, sin ningún recurso humano. Él asumía solo todo el peso de su existencia" (p. 128). La experiencia del cautiverio confirma a Levinas que en la vida vivida como aceptación de la elección se produce la evasión que él buscaba, o que las respuestas a las preguntas que él planteaba y que lo conducían al "corazón de la filosofía" (Levinas, 2011, p. 30) no se encontraban en el plano de la teoría sino en el de la vida misma. El cautiverio es uno de los modos de cumplimiento de la elección que rompe el orden del ser (Levinas, 2013, p. 135).

Cuando Levinas se apropia de la noción de categoría para exponer el rol filosófico del judaísmo, opera al mismo tiempo una resemantización del término, porque difícilmente se lo podría ubicar en alguna de las nociones precedentes. Por un lado, la metafísica aristotélica le es tan ajena como el uso lógico-trascendental kantiano. Por otro, y a pesar de su declarada opción fenomenológica, es precisamente su conocimiento de la intuición en Husserl lo que lo aleja de su concepción categorial, ya que su teoría de la intuición condice con una ontología que Levinas mismo cuestiona (Levinas, 2004a, p. 22). Aunque encuentra en Husserl algunas nociones que serán esenciales para su propio pensamiento, como protoimpresión y síntesis pasiva, la ontología husserliana finalmente lleva a un sujeto trascendental distinto del sujeto-rehén levinasiano. Por el mismo motivo -la crítica de la ontología- no se puede tomar al existencial heideggeriano como sinónimo del uso que Levinas hace de categoría, si bien metodológicamente la figura del existencial se probará más cercana a su filosofía. Al mismo tiempo, y habida cuenta de estas diferencias, Levinas asume funciones para la noción de categoría que tienen vínculos claros con las tareas que le atribuyeron en el pasado.

Si estas consideraciones son correctas, entonces la determinación más adecuada es que el judaísmo es para Levinas una forma del Dasein histórico, reunida y estructurada por una serie de términos y comprensiones particulares de su sentido. Esta forma del existir tiene una primera característica central, que Levinas expone en 1947 y de diversos modos retomará: frente a las filosofías y religiones de la presencia y la actividad, el judaísmo expone una facticidad vinculada con el pasado y la pasividad. El pasado tiene que ver con la idea de creación y elección, es decir, la idea de ser sin haber elegido, y de haber sido elegido al ser. "El pasado que introduce la creación y la elección en la economía del ser, le comunica al presente la gravedad de un hecho, el peso de una existencia" (Levinas, 2002, p. 105). 
Al mismo tiempo, la elección porta consigo no privilegios sino responsabilidades históricas que se juzgan extra-históricamente. La facticidad de la elección se comprende no desde el orgullo del particularismo, sino desde el misterio de la personalidad de quien es hijo y elegido para la responsabilidad. No es casual en este sentido que el pensamiento de Levinas haga eco en las tradiciones surgidas del monoteísmo, donde la responsabilidad se entiende a partir de un llamado que la tradición revela pero que, al mismo tiempo, no se entiende desde la propia historia y más allá de la misma, como una característica de todo sujeto. Es en esta existencia fáctica donde se comprenden las categorías en juego, que tienen la tarea sintético-hermenéutica de reunir experiencias a la luz de significantes que permiten abrir su sentido. Es un uso próximo al de los existenciales heideggerianos, aunque surgidos de la historia de un pueblo y las lecturas de una tradición, y no de la indicación formal a partir de una ontología fundamental. Por eso, cuando Levinas habla de "categoría del ser" puede entenderse como "forma del ser", o sea, del existir, del ser-ahí, atravesado por una serie de significantes, sentidos y experiencias históricas que le hacen ab initio parte de una tradición. Y por eso también "categoría" no puede entenderse en el sentido escolástico de una estructura atemporal histórica que alcanza el ámbito del lenguaje mediante una inteligencia que la nombra, adecuando así ser y pensar.

En el uso levinasiano, la categoría es un dispositivo que sintetiza hermenéuticamente situaciones históricas a la luz de un sentido que atraviesa las experiencias de quienes pertenecen a una tradición. A partir de este sentido históricamente situado, se abren a la comprensión el sentido de otras experiencias de quienes participan o no de esas situaciones y pertenencia. En la síntesis hermenéutica operada por la categoría judaísmo se trata de una "categoría" que no corresponde con el uso lógico-ontológico, sino que es un modo de comprender las experiencias humanas a la luz de la historia y los significantes del judaísmo, al modo de existenciales que no se abren a la luz del ser del Dasein.

En un texto central para nuestro tema, Levinas escribe: "las cosas soportan en tanto que 'materia prima' el logos kerigmático que manifiesta sus trazos en esa materia” (1987, p. 177), y solo así la cosa se muestra como esto o aquello.

Esta caída o accidente, puro abandono al logos sin tener en cuenta la proposición que hará de la cosa la narración a la cual pertenece el logos, es la esencia del 
acusativo. El logos que informa la materia prima, llamándola al orden, es acusación o categoría (p. 177).

El kerigma es para Levinas un modo de categorización y acusación que "llama al orden" a la materia. Inmediatamente, Levinas desmarca ese tipo de "acusación" categorial con origen en el logos de otro tipo, anárquico, expuesto por "la idea de creación", que ya no debe ser pensada en términos de ontología. Pero antes de pasar a esa otra noción de categoría, hay que resaltar aquí que lo que el kerigma hace, según este texto, es entregar la cosa al logos, "sin tener en cuenta la proposición”. No se puede desconectar esta afirmación de la referencia a Rosenzweig citada más arriba, cuando Levinas dice que el judaísmo es una categoría del ser y no una enseñanza cuyas afirmaciones pueden ser verdaderas o falsas. Ambas afirmaciones dan cuenta del impacto que Levinas recibió en su primer encuentro con Heidegger, cuando este afirmaba que la verdad no está en la proposición sino en el Dasein (Casper, 2008a, p. 22).

Lo primero, entonces, es una caída, declinación, previa a toda reconstrucción del sentido que el logos haga a posteriori. Hay una receptividad de aquello que el logos "acusa" al categorizar. Esta receptividad primera, que la fenomenología abre desde la intencionalidad como prototipo de toda trascendencia (Levinas, 2004a, p. 68), es radicalizada y desbordada por una relación que revierte la acusación sobre el sujeto. Esto es esencial para comprender el rol que el acusativo tiene en Levinas. Ya no se trata de dar unidad a la multiplicidad fenoménica mediante un concepto, sino que cuando el "fenómeno" es el Otro, entonces se da un doble exceso: exceso respecto del fenómeno y respecto de las capacidades del sujeto. El Otro trastorna, invierte, conmueve y desfasa la intencionalidad del sujeto que quiere constituir sentido en el mundo (Casper, 2008a, p. 48). El sujeto ya no puede practicar una categorización ni al modo ontológico, ni trascendental, ni por una intuición fenomenológica. Excede además los existenciales que la ontología fundamental encontraba en el Dasein, porque la acusación no es una descripción ontológica sino un modo de relación de respuesta, de responsabilidad. Solo la ética, en términos levinasianos, es capaz de exponer esa acusación categorizante, y es el judaísmo lo que le da los términos para reunir y comprender esa experiencia. Sin que sea contradictorio, los existenciales que caracterizan el modo de ser para Otro descripto por Levinas pueden operar su reunión y síntesis a partir de categorías elaboradas desde la hermenéutica de la experiencia judía. 
Desde esta aproximación, vale exponer el modo en que el judaísmo como categoría permite entender el rol de síntesis hermenéutica existencial de experiencias que constituyen la subjetividad. A continuación se presentan cuatro categorías nacidas de la tradición judía que permiten comprender experiencias estructurales que caracterizan la relación interhumana.

\subsection{EXPERIENCIAS DEL OTRO: SEPARACIÓN Y GLORLA}

Una CARACTERÍstica básica del modo de existir en relación con Otro es reconociendo la infinitud de la separación entre el Otro y uno mismo, al mismo tiempo que la separación, la manifestación del Otro revela un mandato. Pero el mandato sería justificable desde otro lugar -por ejemplo, alguna reflexión trascendental- si no se comprende plenamente esa separación. Las dos obras máximas de Levinas sintetizan esta separación como "exterioridad" y "gloria”. Posiblemente debido a que Levinas es consciente de que el judaísmo excede largamente la noción institucional de religión, es que resignifica el término para hacerlo coextensivo a la ética en tanto modo de dar cuenta y respuesta de esa alteridad separada: "proponemos llamar religión a la ligadura que se establece entre el Mismo y el Otro, sin constituir una totalidad” (Levinas, 1995, p. 64; véase también pp. 102104). La "religión" sostiene esa relación de separación absuelta-ab-alio-solutumal tiempo que reconoce que la "situación última" donde se da la misma es en el cara-a-cara (Levinas, 1995, p. 104).

Así como la inteligencia y tematización de Dios son imposibles, como una y otra vez el judaísmo lo muestra en su siempre tensa y fecunda relación con la filosofía, del mismo modo la relación con otro respeta la "trascendencia total del Otro sin ser hechizada por él” (Levinas, 1995, p. 101). La relación con Dios y con el Otro no es irracional, pero tampoco tematizable. Su accesibilidad primera se da en la justicia, y la primera justicia indica no solo el mandamiento "no matar", sino además el de "acompañar a otro en su tener-que-morir, en su finitud" (Levinas-Casper, 2012, pp. 16 y ss.). Y la condición de posibilidad originaria de la misma es el reconocimiento de la separación del Otro exterior. Esa exterioridad muestra que la significación que proveen las categorías no es un acontecimiento ontológico, pero tampoco intuitivo: significar no es dar, sino que la manifestación del Otro es discurso que "deshace en todo momento la 
forma que ofrece" (Levinas, 1995, p. 89). Puede deshacer sin caer en la nada porque su manifestación persiste, incluso bajo la más inhumana de las figuras. Se expresa con "rectitud" o "sinceridad", en un estado de "gloria". Al igual que sucede con la shekhinah hebrea, la "gloria" trasciende al sujeto y al mismo tiempo necesita de él para que se dé su revelación; rompe su tematización pero al mismo tiempo lo inviste: "la gloria, al hacer estallar el tema, significa de modo positivo, al margen del logos, la extradición del sujeto que reposa sobre sí hasta aquello que jamás ha asumido porque, a partir de un pasado irrepresentable, fue sensible a la provocación que nunca se ha presentado, pero que ha tocado de modo traumático" (Levinas, 1987, p. 220). Para Levinas, la figura de Adán sirve como expresión de una disposición del sujeto que no es origen de sí, sino que es convocado a responder an-árquicamente, previo a toda decisión. $\mathrm{Al}$ mismo tiempo, esta obligación única, siempre individual y no universalizable, permite que el sujeto se entienda como "respuesta imprevisible del elegido" (Levinas, 1987, p. 221).

El judaísmo funciona como una "religión" cuyo contenido no se reduce a sus prácticas o textos, sino que se origina en un encuentro traumático con una alteridad separada y gloriosa, que de alguna manera convoca y obliga al sujeto, eligiéndolo de una manera tal que permite en la respuesta su identidad. Característica ineludible de esa "religión" es su capacidad de sostener una relación entre términos absueltos, sin una síntesis o totalización posterior (Levinas, 1995, pp. 102-104). El vínculo del sujeto con el Otro nace por el modo en que Otro elige al sujeto y establece en él un deseo, deseo de responder, responsabilidad, a un mandato y a una prohibición: no matarlo, no dejarlo solo en su mortalidad (Levinas \& Casper, 2012, p. 17).

\subsection{EXPERIENCIAS DE LA RESPONSABILIDAD: ELECCIÓN Y SUSTITUCIÓN}

LA NOCIÓN DE ELECCIÓN y su vínculo con la responsabilidad es inseparable de la experiencia judía del mundo. Levinas lo vuelve patente ya en los momentos más cruentos de su padecimiento personal en el Stalag 1492, y de modo pleno luego, cuando cobra conciencia de la masacre. Si la categoría en tanto kerigma es el ordenamiento del fenómeno, en la relación con el Otro el sujeto se reconoce declinado en acusativo, "colocado de entrada en acusativo" (Levinas, 1987, p. 108), obligado a dar cuenta de su lugar en el mundo y de su libertad de cara a 
Otro. La versión moderna del sujeto autofundante, cuya libertad es origen de la norma, se ve anticipada por otra relación previa, donde la libertad es cuestionada en su conatus porque se reconoce investida, dependiente del Otro separado y trascendente. La responsabilidad ante la llamada de otro -que tiene la misma estructura de la pasividad más pasiva que toda pasividad que pueda ser recuperada por un acto, como sucede con las ideas de creación y elección- pone al sujeto desde siempre-ya en una situación de tener que dar cuenta de sí y su propio ser ante otro, y esa situación es el punto de partida de su identidad única.

Pero "la singularidad del sujeto no es la unicidad de un único (hápax)" (Levinas, 1987, p. 171). La categoría aristotélica de sustancia se debe a la conjunción de materia y forma, adquiriendo su unicidad mediante la escisión de ese fragmento único de materia respecto del resto. En cambio, el "sí mismo" levinasiano adquiere su identidad no por "una quididad individuada, gracias a una diferencia específica última inherente al cuerpo o al carácter, o gracias a la unicidad de una coyuntura natural o histórica. Reside en la unicidad del asignado" (Levinas, 1987, p. 171). Esto no elimina el valor de materialidad e historicidad, sino que las reubica a partir de una relación de asignación con el Otro. Tampoco indica la posición de un sujeto que piensa la manifestación del fenómeno apropiándose del mismo mediante sus capacidades trascendentales (Levinas, 1987, p. 161). En cambio, ser-asignado incluye ser-elegido y al mismo tiempo la tarea de alcanzar la propia identidad respondiendo a la "exigencia irrecusable del otro", que señala una pasividad del sujeto que es más pasiva que la pasividad de las cosas que soportan el "logos kerigmático" que las categoriza (Levinas, 1987, pp. 176 y ss.).

El Otro es infinito, separado, pero también "prójimo". El lenguaje bíblico es ineludible, no solo por el significante utilizado sino por cómo se lo semantiza: el prójimo obsesiona porque escapa a toda relación recíproca y simétrica, es una relación irreversible, y eso testimonia no una identidad original ni el límite impuesto por la negación, "sino lo más acá pre-originario de la abnegación", la identificación de sí como "uno-para-el-otro", exposición al contacto del decir, piel o rostro del Otro (Levinas, 1987, pp. 144 y ss.). Por tener la subjetividad misma una relación de vocación hacia Otro que no se salda, tiene también la forma de un mandamiento. El mandamiento no es simple obligación moralizante, es más y menos: asume la forma de una persecución, porque revela que la asignación muestra al Otro en uno mismo, antes de todo diálogo, tematización 
o negociación (Levinas, 1987, p. 189), pero al mismo tiempo deja un amplio campo de libertad para la respuesta. Esta "asignación” golpea al corazón de la idea moderna de individuo atómico y auto-fundado: la unicidad del elegido por Otro para la responsabilidad es anterior al individuo mismo (Levinas, 2001, p. 292). Es por esa experiencia de alteración originaria de sí, que el inicio y cumplimiento del sujeto no solo rompen los cánones formales habituales de la espacialidad, por la separación absoluta del Otro que se revela al interior del mismo como mandato, sino también los de la temporalidad.

Ser uno-para-el-otro indica que la estructura de la subjetividad no es retorno de la conciencia a sí misma sino lo que Levinas denomina "sustitución". La palabra tiene reminiscencias judeocristianas (los casos de Isaac y Jesús), pero en Levinas asume una exposición filosófica: el sí mismo no logra su identidad por una conciencia o libertad ejercida en el tiempo, sino a partir de descubrir su condición de rehén de otro que le llama a la responsabilidad y en la respuesta misma el sujeto advierte su asignación irremplazable. Al descubrir su pasividad el yo se reconoce "intercambiable" en su responsabilidad por otros. La elección se vincula así con la sustitución en tanto configuración de la subjetividad: "Toda acusación es persecución, del mismo modo que toda alabanza, recompensa o punición interpersonales suponen la subjetividad del yo, la sustitución, la posibilidad de ponerse en lugar del otro" (Levinas, 1987, p. 188). No se trata de decidirse por la empatía, sino de reconocer la estructura de una subjetividad dependiente del otro que elige y asigna al sujeto para que asuma su lugar de responsable por otro.

\subsection{EXPERIENCIAS DE LA TEMPORALIDAD: CREACIÓN Y REDENCIÓN}

LA COMPRENSIÓN LEVINASIANA DEL TIEMPO opera dos novedades significativas. Por un lado, Levinas opera una "desformalización" de la comprensión del tiempo (Levinas, 2001, p. 203; Gibbs, 1992, p. 27). Por otro lado, opera una historización de la temporalidad del Dasein. En ambas operaciones, el judaísmo tiene un rol central, en la primera por las nociones de temporalidad de los "eventos" monoteístas de creación y redención, y en la segunda por la atención del rol de Israel en la historia de Occidente. Levinas afirma la influencia de Rosenzweig en tanto su filosofía logró "desformalizar" la noción del tiempo a partir de la vinculación con las categorías bíblicas de creación, revelación y redención. Esta 
desformalización de la secuencia enumerada aristotélica y de las intuiciones puras y vacías kantianas, así como la irrupción en la secuencia de "experiencias" que no condicen con un pasado, presente y futuros "vacíos", sino cargados de sentido, tuvieron un gran impacto en Levinas².

Aun reconociendo el valor de la fenomenología de la temporalidad y sus raíces agustinianas para enfrentar la comprensión aristotélica y kantiana del tiempo, "se estaría equivocado al situar el tiempo interior en el tiempo objetivo, como lo hace Husserl” (Levinas, 1995, p. 81). El tiempo no es una síntesis presente ejercida por la correlación intencional del sujeto trascendental, sino que se da a partir de una relación con contenidos i-rrepresentables, imposibles de correlacionar mediante una donación de sentido a la altura de las capacidades subjetivas, pero que preñan de contenido y constituyen la vivencia temporal. Sucede que "la separación solo es radical si cada ser tiene su tiempo, es decir su interioridad, si cada tiempo no es absorbido en el tiempo universal" (Levinas, 1995, p. 81). El tiempo compartido y común no da cuenta de la temporalidad subjetiva, no meramente por su carácter subjetivo e individual, sino porque la subjetividad de cada sujeto se constituye desde su relación con la alteridad. Y la tradición monoteísta provee de una síntesis hermenéutica de posibles relaciones con las nociones que remiten al pasado irrecuperable desde el cual se origina la subjetividad relacional y al futuro im-presentable de su cumplimiento.

En esto Levinas también muestra su deuda y superación respecto de Heidegger: la ex-sistencia en tanto temporalidad, los éxtasis por los que el Dasein recupera su pasado y se proyecta hacia sus posibilidades más propias, son interpretados por Levinas como la recepción de una convocatoria a la que el sujeto busca dar plena respuesta en la historia, al tiempo que sabe que la misma es imposible, como lo prueba la consumación de su finitud -la muerte-. Autenticidad ya no es asumir la propia realización saliendo de sí en vistas de la muerte, sino partir de no ser el propio origen y de estar convocado a una obra, que sin embargo trasciende su propia finitud. Desde su juventud Levinas plantea que es posible establecer con el comienzo "otra relación que aquella de 'poder o de no poder”, y

2 No es dato menor que también las lecciones de Heidegger sobre la temporalidad de la experiencia cristiana parten de la facticidad de la experiencia vivida a la luz de la parousia y el "sentido de acontecimiento" con que se comprende al tiempo (Heidegger, 2006). 
con el porvenir "otra relación que aquella del 'proyecto"' (Levinas, 2009, p. 102), pero que ello implicará posiblemente "salir de la fenomenología". Lo que él propone es que "la relación con el comienzo en lugar de constituir la desgracia de la Geworfenheit, [...] debe aportar la fe en el Padre, la seguridad de un mundo creado" (Levinas, 2009, p. 102). Para él, "la falta" no está en "en el origen pasado, en este 'profundo antaño, antaño nunca excesivo', sino en el origen del sujeto -del orgullo esencial del yo-, que ignora el pasado, resolviendo sobre él, a partir de su acontecimiento presente" (Levinas, 2009, p. 103).

Según Casper, cuando Levinas postula al ente como creado de la nada implica "la 'cualidad básica' de todas las realidades", porque el acceso que la noción de creación posibilita no es el "del sentido de ser como 'presencia' - Anwesenheit-y 'existencia disponible' -Vorbandenheit-" (Heidegger), ni el de la "hermenéutica del 'ser' humano" (Husserl), sino el sentido de "ser" abierto por el "nuevo pensamiento" de Rosenzweig, que le permite sostener "que el yo se encuentra ya en la relación de 'ser concernido por el Otro"' (Casper, 2008a, pp. 77 y ss.) y es desde la experiencia de su rostro como se llega a la idea de creación. La "creación" indica tanto la pasividad inicial del sujeto como el tipo de temporalidad en la que surge su propia identidad: un pasado inmemorial, irrecuperable, previo a todo compromiso, donde la autoridad del Otro se manifiesta y a partir de la cual el sujeto le testimonia mediante el uno-para-el-Otro (Levinas, 1987, p. 228). Ese testimonio es un tipo de significación profética, que manifiesta la "intriga" presente en la ética y el lenguaje ${ }^{3}$.

3 A pesar de la relevancia de este concepto ético de la creación en Levinas no podemos olvidar otra fuente de la desformalización que el mismo Levinas asume de Rosenzweig. Se trata del rol que tuvo - coetáneamente con el judaísmo ilustrado, rabínico y racionalista- la comprensión de la creación que se sintetiza en la cábala. Frente a la tradición metafísica cristiana, que se basa sobre todo en la discusión de la libertad y omnipotencia divinas capaces de crear sin causa material, la cábala con la tradición mística sostiene que la creación es tal "desde Dios mismo" (Scholem, 2008, p. 59). La totalidad de Dios antes de la creación y su contracción para dar lugar a lo que hay, significa también otro modo de pensar lo que hay, la experiencia de la creación y su desformalización de la idea del tiempo, así como los problemas éticos vinculados al mal y a la teodicea. De allí que Habermas subraye que lo notable en Scholem no es solo su erudición histórica respecto de los movimientos heréticos que en el judaísmo vincularon esa visión de la creación con ciertos modelos mesiánicos de redención, sino sobre todo cómo esa potencia herética mesiánica, que buscaba -en términos de Rosenzweig- "forzar" la venida del Reino, se volvió en la Ilustración hacia fines inmanentes y políticos (Habermas, 2001, p. 168). Es decir, en ambas vertientes del judaísmo la creación se muestra 
Creación no significa causalidad metafísica ni participación en el orden del ser, sino separación, libertad y llamada. Es manifestación de excedencia y condición de posibilidad para que lo infinito pueda suceder (Levinas, 1995, p. 231). La creación como relación con un pasado irrecuperable y que nunca es suficientemente pasado, signo de trascendencia y separación, es también requisito de la justicia del sujeto de cara al Otro (Levinas, 1987, p. 172; 1995, p. 199). Al mismo tiempo, el sujeto debe responder por un futuro que siempre permanece futuro. El triunfo "puro" mesiánico, "tiempo acabado" exige "a la vez, un tiempo infinito y un tiempo que podrá sellar" (Levinas, 1995, p. 292). Como sucede en Rosenzweig, la redención es el acontecimiento ético que concreta la conciencia mesiánica, pero que nunca provoca ni agota definitivamente la venida del Reino, "siempre es futuro, pero es futuro siempre" (Rosenzweig, 1997, p. 273). Por eso, el mesianismo no significa la concreción en la historia del mundo redimido -de allí la necesidad y el escepticismo respecto de los grandes proyectos políticos y la necesidad de la "pequeña bondad" como criterio regulador de las obras-, sino el modo constante en que el sujeto responde al bien de modo siempre limitado y corregible, aunque traumático.

A partir de Levinas y Rosenzweig, Casper afirma que las experiencias de la existencia no encuentran su clave en las categorías del conocimiento, pues este no alcanza el misterio de la subjetividad ni de la historia (Casper, 2008b, pp. 28 y ss.). A diferencia de las filosofías del saber, que "operan con la ayuda de nociones", la experiencia judía vivida a partir de la relectura de antiguos significantes considera que "lo esencial del saber son los seres". Por ejemplo, el evento histórico que signará toda otra reflexión sobre la redención: "la salida de Egipto constituye el absoluto y no la relación entre substancia y accidentes o entre pesos atómicos" (Levinas, 2013, p. 114). Contra todo pensamiento que subsume los individuos en una totalidad, el judaísmo privilegia los hechos que constituyen la liberación de los individuos, porque lo que persigue no es explicar por el logos; lo

no como pasado acabado sino como actividad continua y demandante a nivel subjetivo. Esta breve nota no exime de la lectura del fundamental texto de Scholem, pero sirve como advertencia de una afinidad profunda entre las versiones "místicas" y "racionalistas" del judaísmo posterior a la Ilustración, en tanto la actividad ética en el mundo significa la continuación de la creación en tanto manifestación continua de lo divino. 
"absoluto" no es la conciencia, como en Husserl, sino la salvación, la vida por encima de la teoría. Estos pensamientos escritos a la luz de un acontecimiento brutal, donde la demanda de redención se vuelve acuciante y remite a la experiencia básica de liberación de la esclavitud, no ceden luego, en la "normalización" de la vida, sino que adquieren mayor consistencia filosófica. La "persecución" de la responsabilidad que el elegido asume como "rehén" y "a su pesar" (Levinas, 1987, p. 112), sin compromiso ni culpa previa, por su propia condición, contiene la estructura fundamental que la historia reveló como carga violenta y responsabilidad al judaísmo. De allí que la ética levinasiana sea todo menos un voluntarismo bienhechor.

Además de las ideas de creación y redención, hay que resaltar un tercer elemento proveniente de la temporalidad comprendida desde el judaísmo como categoría del ser: la inmanencia de la historia se juzga desde un punto de vista trascendente. En términos de Rosenzweig, el judaísmo no se ve llevado por los vaivenes de la historia -como el cristianismo- ya que está donde los demás quieren llegar; es decir, su persistencia en los mandamientos le otorga un quicio desde el cual moverse en la historia y juzgarla. La historia siempre se absuelve a sí misma al hallar razones suficientes para cada hecho: "el juicio de la historia se pronuncia siempre por contumacia” (Levinas, 1995, p. 256). Pero es precisamente contra ese tipo de relativismo (que no es relatividad) contra el que resiste el judaísmo, aunque sin caer en una fundamentación sub specie aeternitatis:

Por eso nos negamos a ver a 'Dios en la historia', porque no queremos ver la historia (en su relación religiosa) como imagen, como ser, sino que negamos a Dios en ella, para restaurarlo en el proceso por el cual ella deviene. Vemos a Dios en cada acontecimiento ético, pero no en el todo realizado, en la historia. Pues para qué necesitaríamos a Dios, si la historia fuese divina, si toda acción que fluye en esa cuenca fuera sin más divina, entonces estaría justificada (Rosenzweig, 1979, p. 112).

Esto no quita el valor de la historia, por el contrario, la valora sin idolatrarla, sin subrogar las decisiones del sujeto en su unicidad a algún tipo de universal vacío. 


\subsection{EXPERIENCLAS DEL LENGUAJE: PROFETISMO}

UNA DE LAS CARACTERÍSTICAS que Levinas identifica en la tradición judía es su constante interpelación de los eventos históricos desde su tradición escritural. Pero además, algo constante en Levinas es que ese movimiento lo lleva a identificar en toda escritura señales de lo trascendente pasibles de ser reconocidas por las "categorías" del judaísmo y puestas filosóficamente a disposición de cualquier ser humano. De allí su constante remisión a la poesía, a la novela, al teatro. Del mismo modo que sucede con el texto bíblico, este sería tergiversado en su sentido si se buscasen en él modos de reducir la trascendencia al concepto y a categorías ontológicas, abandonando su inspiración profética.

Estos textos son modos de "epifanía", en tanto ponen por escrito lo que sucede cuando el Otro enfrenta al sujeto y este habla: al hablar se revela el mandamiento en su propia boca, en su propia lectura, en su propia interpretación. La "orden" no es previa, como la elección no es previa a una libertad, sino que en la respuesta y obediencia ella se expresa: "puede llamarse profetismo este retorno en el que la percepción de la orden coincide con la significación de esta orden realizada por el que obedece a ella" (Levinas, 1987, p. 226)4. Y la primera significación es presentarse de golpe, en acusativo, en el "heme aquî". Todo psiquismo tiene esa base de respuesta-responsable, por lo que "toda la espiritualidad del hombre” es profética. De allí que el lenguaje profético no está solo en textos inspirados, también la respuesta del sujeto es profética:

La palabra profética responde esencialmente a la epifanía del rostro, dobla todo discurso, no como un discurso sobre temas morales, sino como momento irreductible del discurso suscitado esencialmente por la epifanía del rostro en tanto que testimonia la presencia del tercero, de toda la humanidad (Levinas, 1995, p. 226).

El lenguaje bíblico del encuentro con Otro que invoca y provoca es el modelo del testimonio que luego puede volverse kerigma y teología (Levinas, 1987, p. 227). Al estar sometidas a la historia y sus instituciones, estas pueden olvidar

4 La traducción de "perception de l’ordre" por "percepción del orden” en la edición de Sígueme no parece dar cuenta del sentido a la luz de toda la oración, por lo que nos permitimos cambiarla. 
una y otra vez el encuentro primero y su epifanía. Sucede que encuentro y epifanía pueden ser tematizados, lo que significa una condición tan imprescindible como riesgosa. De allí que el profetismo del lenguaje puede una y otra vez volver a despertar la intriga ética en el tiempo.

\section{3. ¿Es el judaísmo una ontología?}

NO ES IMPENSABLE que a partir de esta reconstrucción del sentido que Levinas atribuye al judaísmo como "categoría del ser" y punto de partida alternativo a la analítica existencial del Dasein surja una objeción importante. Si se atiende a la idea central de De la evasión y se reconstruyen las figuras que la misma asumió a lo largo de su recorrido intelectual -llegando al bien que está más allá de la esencia, en el cual la relación ética se manifiesta de otro modo que ser-entonces el vínculo del judaísmo con algún tipo de categorización capaz de fungir a modo de los existenciales podría significar una nueva ontologización de la experiencia judía. Esta ontologización se podría comprender bajo la figura de una "facticidad" que encadena a los miembros de ese colectivo a una "esencia", históricamente fijada, quizás, pero con irremisibles efectos de verdad. El propio Levinas indica este peligro en textos previos a la guerra y continúa su reflexión después de su liberación. El opúsculo Etrre juif de 1947 aborda la "cuestión judía” frente a los reclamos políticos surgidos ante la evidencia de la barbarie nazi. La respuesta de Levinas reconoce los modos de entificar al judaísmo, empezando por el modelo racista y la respuesta sartreana, que al mismo tiempo reconoce en el racista la mirada entificadora y propone que el judío -ante la ausencia de una esencia propia-, asuma su situación y se haga su propia esencia (Levinas, 2002, p. 103). También reconoce los discursos de cierto naturalismo metafísico que reducen la existencia judía a un hecho natural, con la misma lógica de lucha por la supervivencia que los demás puebloss. Pero "ser judío -dice Levinas (2002)- no es solamente buscar un refugio en el mundo, sino sentirse un lugar en la economía

5 No se puede separar la crítica a esta "normalización” del judaísmo de la interpretación de Rosenzweig y su resistencia a considerar al judaísmo como otro pueblo más en la lógica de la guerra por la supervivencia nacional (Rosenzweig, 1997, pp. 390 y ss.). Obviamente, este análisis no puede sostenerse incólume después de la Shoah. 
del ser" (p. 99)6. Ese lugar no es la reducción al modelo moral de su decálogo, sino una "idea", que es propia de esa tradición y al mismo tiempo no le pertenece,

[...] porque volcada al patrimonio común de la humanidad, la idea ya no le pertenece. La idea, finalmente, no tiene origen. Ella es lo menos privado que uno tiene; un mundo donde uno se comunica por medio de ideas es un mundo de pares (Levinas, 2002, p. 100).

Esa idea es que la facticidad judía significa el ingreso de lo religioso en el mundo, particularmente bajo la forma de una elección sin privilegios, pero con responsabilidades, en la cual "el pasado que la creación y la elección introducen en la economía del ser le comunica al presente la gravedad de un hecho, el peso de una existencia y como un asiento" (Levinas, 2002, p. 104). La "evasión" de este naturalismo no debe confundirse con el tipo de "evasión" de una noción reductiva del ser, por la que aboga a lo largo de su filosofía.

Es así como el vínculo con el ser del judaísmo no es el de una estructura ontológica fijada por algún motivo biológico o por la cristalización históricamente fijada a través de las creencias y prácticas de una comunidad, sino un desfase de la economía del ser. Es decir, es una experiencia que permite retomar las "categorías" de la existencia desde sentidos expresados por significantes antiguos, siempre menesterosos de resignificación, pero también siempre críticos de las consolidaciones semánticas que fueron cristalizándose en los diversos presentes históricos. De allí que Levinas nunca deje de afirmar que su abordaje es filosófico, pero al mismo tiempo eso no significa que se reduzca solo a la aventura filosófica. Reconoce su situacionalidad hermenéutica pero al mismo tiempo cuenta con las herramientas para traducirla al "griego", o sea al lenguaje filosófico comprensible por quienes no provienen de ese origen. Como dice Benny Lévy en su interpretación de Levinas, la filosofía siempre sostuvo solo una aventura del espíritu, llegar con el intelecto hasta lo que se pueda pensar. Eso es Grecia y la línea que va de Aristóteles a Heidegger, y se reencuentra en las tesis políticas de diversas proveniencias que no dejan entrar otra sabiduría que rompa el modelo universalista griego (Lévy, 2005, p. 234). Pero la lectura levinasiana es un desfase de ese modelo. Al mismo tiempo Levinas rechaza la maldición talmúdica a quien 
enseñe a su hijo la sabiduría griega (Levinas, 1982, p. 44). O sea, Levinas inicia su pensamiento desde la filosofía, con la carga ontologizante que le reconoce, pero niega que sea tanto una maldición como la totalidad de lo pensable. Por eso muestra críticamente la violencia de esa visión reductiva a la finitud de lo que es. Así, no se puede entender la obra de Levinas reduciéndola a una fenomenología como las de Husserl o Heidegger, ni a una interpretación del judaísmo, solo comprensible para quienes comparten esa tradición (Lévy, 2005, p. 228), pero tampoco de modo separado de esas formaciones intelectuales. Se puede entender cómo para él el judaísmo es la "categoría" o la disrupción en la "economía del ser", que permite acceder por la dialéctica histórica de sus significantes y sus vivencias a un modo diverso de comprender la existencia a la luz de la responsabilidad.

Una anotación significativa de Lévy (2002, pp. 109 y ss.) nos permite ver una especie de contradicción aparente en dos textos de la inmediata posguerra: la fenomenología de la existencia humana en El tiempo y el otro y De la existencia al existente parecen pensadas de modo atemporal. Si bien la temporalidad es esencial, se trata de una temporalidad a nivel constitutivo del ser, sin aducir a una temporalidad histórica particular. Al mismo tiempo, en $\hat{E}$ tre juif indica que ese pasado se relaciona con creación y elección, un "pasado" que luego en De otro modo que ser explicitará como más pasado que todo pasado cronológico, y que es como "peso de una existencia”. Es volver a un pasado, pero no vinculado con la biología o la cultura, sino con una experiencia nacida en la tradición religiosa y renovada en la ética. Ya en 1934 decía que la tragedia del hitlerismo significó al mismo tiempo devolver al judío a la "irremisibilidad de su ser", a una condición de la que no puede salir, que al mismo tiempo es un encadenamiento al cuerpo que caracteriza a todo hombre (Levinas, 1997, p. 19). Aunque ese vínculo inexorable con su historia le es revelado al judío por la violencia del antisemitismo, ya ante otras preocupaciones menos dramáticas, como por ejemplo la educación en el contexto de asimilación, Levinas afirma que "el judío está ineludiblemente clavado a su judaísmo" (Levinas, 1935, p. 4). De modo paradojal, el orden del ser se confirma por un lado como ineludible -y en el caso del judaísmo esto se refuerza por la propia conciencia histórica, pero sobre todo por la mirada del perseguidor-, pero en el seno de ese orden ineludible se da la intriga de la responsabilidad, convocada por ese "pasado" de creación y elección, que permite desfasar el orden inmanente del ser y su imposición a partir de la responsabilidad. Levinas 
está lejos del orden de la autenticidad heideggeriana, que entiende que el ente humano recupera su existencia a la luz de una correspondencia auténtica con sus posibilidades propias, pero también de una especie de particularismo comunitario, religioso o cultural, que románticamente le da sentido. Ambos serían modelos de sujeción al orden inmanente del ser. En cambio, la idea de trascendencia por vía de la responsabilidad, convocada por un pasado no cronológicamente fijable y sin embargo siempre activo, implica salir del orden de la cronología, la totalidad y el ser, para responder de un modo irreemplazable a la convocatoria única a la responsabilidad.

La disputada idea levinasiana de la ética como filosofía primera y del carácter secundario, no fundamental, de la ontología, permiten analizar -incluso a partir de sus críticos - cómo esa relación primera con la alteridad demandante, que la fenomenología expone y que encuentra en el judaísmo un lenguaje para hacerlo, al mismo tiempo pertenece al orden de lo que hay pero excede el fenómeno. Para exponer esa experiencia de lo que excede y desfasa el orden ontológico Levinas recurre a nociones como exterioridad, alteridad, diacronía. Esta elaboración de Levinas significa una relectura notable que, sin renunciar totalmente al tipo de análisis provisto por la fenomenología existencial, critica la ontología heideggeriana y va más allá de ella, en tanto Levinas fecunda ese análisis con una experiencia de raigambre judía que la propia fenomenología existencial era por sí incapaz de asumir ${ }^{8}$.

7 Por ejemplo, la crítica de Úbeda (2014) a la idea de "filosofía primera", en tanto considera que al ubicar la relación con otro en lugar primario no permite el paso de lo individual a lo social -que Levinas tomaría como garantizado por la experiencia de ser parte de un pueblo vinculado por la Torá- ni permitiría ya una separación entre filosofías primera y segunda. Pero el punto de Levinas respecto de la tradición heredada no es el regodeo entre los correligionarios sino la posibilidad de presentarla filosóficamente, es decir, universalmente traducible y comprensible, también para quienes no son parte, con el fin de abrir dicho sentido en sus propias experiencias.

8 Es notable el valor del nuevo trabajo de B. Casper agregado en la reedición de su obra clásica Das dialogische Denken, "Emmanuel Levinas - Dasein als Leibbürge für den Anderen" (Casper, 2017, p. 356-387), en tanto reconstruye sistemáticamente la relación de Levinas con la ontología fundamental y su superación. 
ESTE TRABAJO INICIA con el acicate de la pregunta levinasiana por una especie de disyunción respecto del punto de partida de la filosofía, o sea, si se ha de partir de la ontología fundamental del Dasein y sus existenciales, que son universales y ahistóricos, aunque la temporalidad les sea constitutiva; o si el inicio ha de ser la experiencia situada del judaísmo, que a su vez lo convierte así en "categoría del ser". Esto lleva al mismo tiempo a la pregunta por la autenticidad, en tanto si la filosofía conlleva la posibilidad de indagar las condiciones del Dasein para su existencia auténtica como apropiación de sus posibilidades más propias inherentes al ser, o si se trata de asumir una posibilidad diversa, que está más allá del orden del ser, no por negarlo sino por trascenderlo en vistas de la relación con Otro signada por la responsabilidad. Para entender el sentido mismo de la pregunta, y para evitar erróneas dicotomías (por ejemplo, la escisión tajante del pensamiento de Heidegger y el de Levinas), este trabajo reconstruyó el sentido de "categoría” y el modo en que dicho término puede asumirse en la obra de Levinas y en su aplicación al judaísmo. De este modo se pudo constatar cómo los existenciales solo adquieren su dimensión histórica, en el caso de Levinas, a partir de su imbricación en la experiencia judía, que trasmuta radicalmente su sentido y estructura. Se trata de un modo de "categoría" que ni corresponde a un sujeto trascendental ni a la ontología fundamental, sino al modo en que el sujeto ha sido atravesado por una historia de sentidos y comprensiones - particularmente ligadas a la alteridad, responsabilidad, temporalidad y lenguaje- que solo son comprensibles a la luz de una historia de sentidos alimentados por vivencias del pueblo judío. La labor filosófica muestra, sin embargo, que no es precisa la pertenencia comunitaria para reconocer esa experiencia radical aportada por tal comunidad. Es así que tales sentidos y comprensiones no significan ontologizar un particularismo, ya que dicha experiencia es abierta a quien se permita abrir los sentidos portados por esa exposición, allende su pertenencia comunitaria particular.

Levinas (1995) afirma que el "psiquismo" es un "acontecimiento en el ser”, una "modalidad del ser" (p. 77). La existencia humana se estructura a partir de la relación con Otro que permite ese modo de ser. El judaísmo le provee a Levinas de los significantes que agrupan campos esenciales de esa existencia: la gloria del Otro separado y la responsabilidad frente a este, la temporalidad desformalizada por 
el ingreso de experiencias no objetivables y la inspiración profética del lenguaje. Ciertamente no son las únicas expresiones, aunque sí son aquellas donde es más visible en su obra el modo en que la filosofía va hacia esas "significaciones primeras", que "ya tienen un pasado". La tarea ontológica y trascendental de las categorías se ve anticipada por significantes portadores de un sentido y constituidos en la experiencia histórica, en este caso del pueblo y los textos denominados judaísmo. Paradójicamente, el particularismo judío revela una condición universal del sujeto como asignado, condiciona la universalidad y pone en juicio la historia precisamente por haber sido víctima de algunas de sus peores violencias (Levinas, 2004, pp. 101-111). Su testimonio del mandamiento "al margen de la historia" permite ponerla en juicio de un modo en que la alteridad sea efectivamente respetada.

En nuestros días, el renovado interés de pensadores sin compromisos religiosos, como, por ejemplo, Habermas, Žižek o Butler, ha puesto de relieve que categorías heredadas del monoteísmo judío y cristiano tienen el valor de abrir contenidos que exceden la utilidad cultural y política de servir como homogeneizadores al servicio de fines estatales. Las "categorías" del judaísmo como "acontecimiento del ser" se muestran como desafío revitalizante a nuestras discusiones éticas y prácticas políticas.

Pero también se desprende una segunda conclusión. Si gracias a la filosofía de Levinas el judaísmo se ha mostrado como tradición fecunda para expresar algunas experiencias humanas fundamentales, esto significa un llamado de atención a no desatender tradiciones simbólicas menos difundidas, ocultadas por las tradiciones más influyentes. Finalmente, es preciso agregar que en el mundo latinoamericano, y sobre todo en las filosofías que no pretendieron ser solo comentarios de autores o corrientes de los países centrales sino una reflexión situada a partir de las experiencias, historias, valores y símbolos latinoamericanos -como es el caso de algunos autores relevantes de la filosofía de la liberación (Fonti, 2007) - la experiencia religiosa no carece de influencia en la filosofía, tarea en la que Levinas se muestra como inspiración fecunda. Nuevamente, y con un modelo análogo a la "categoría" del judaísmo, no se trata de ontologizar un elemento particular (religioso, étnico, cultural, etc.), sino de ver de qué modos la existencia humana se ha desplegado en esas condiciones, cuáles han sido las posibilidades abiertas y los horizontes de sentido que se ofrecen desde ellos. 
Referencias

Aristóteles. (2009). Categorias. (Trad. E. Sinnot). Buenos Aires: Colihue.

Baumgartner, H., Gerhardt, G., Konhardt, K., \& Schönrich, G. (1976). Kategorie.J. Ritter, K. Gründer, \& G. Gabriel.(Eds.). Historisches Wörterbuch der Philosophie (Tomo IV) (pp. 712-725). Basel: Schwäbe.

Casper, B. (2008a). Pensar de cara a otro. Elementos delpensamiento de Emmanuel Levinas. (Trad. D. Fonti). Córdoba: EDUCC.

Casper, B. (2008b). Rosenzweige Heidegger. Essereed evento. Brescia: Morcelliana. Casper, B. (2017). Das dialogische Denken. Freiburg/München: Alber.

Fonti, D. (2007). Influences of Levinas in Latin America's Liberation Philosophy. Jahrbuch für Religionsphilosophie, 6, 183-208.

Gibbs, R. (1992). Correlations in Rosenzweig and Levinas. Princeton: Princeton University Press.

Gordon, P. E. (2010). Continental Divide. Heidegger, Cassirer, Davos. Cambridge: Harvard University Press.

Habermas, J. (2001). Israel o Atenas. (Trad. J. C. Velasco Arroyo). Madrid: Trotta.

Heidegger, M. (1997). Ser y tiempo. (Trad. J. E. Rivera). Santiago de Chile: Editorial Universitaria.

Heidegger, M.(2006). Introducción a lafenomenología dela religión. México, D. F.: Fondo de Cultura Económica/Siruela.

Herrmann, F-W. von. (1987). Hermeneutische Phänomenologie des Daseins. Frankfurt: Klostermann.

Husserl, E. (1992). Ideas relativas a una fenomenologia pura y una filosofia fenomenológica. (Trad. J. Gaos). México: Fondo de Cultura Económica.

Husserl, E. (1996). Meditaciones cartesianas. (Trad. J. Gaos, \& M. García-Baró). México D. F.: Fondo de Cultura Económica.

Husserl, E. (1997a). Investigaciones lógicas I. (Trad. M. García Morente, \& J. Gaos). Barcelona: Altaya.

Husserl, E. (1997b). Investigaciones lógicas II. (Trad. M. García Morente, \& J. Gaos). Barcelona: Altaya.

Kant, I. (2007). Crítica de la razón pura. (Trad. M. Caimi). Buenos Aires: Colihue. 
Krämer, H. J. (1967). Arete bei Platon und Aristoteles. Amsterdam: Schippers.

Levinas, E. (1935). L'inspiration religieuse de l'Alliance. Paix et Droit, 15(8), 4.

Levinas, E. (1951). L'ontologie est-elle fondamentale? Revue de Métaphysique et de Morale, 56(1), 88-98.

Levinas, E. (1982). L' au-delà du verset. Paris: Minuit.

Levinas, E. (1987). De otro modo que ser o más allá de la esencia. (Trad. A. Pintor Ramos). Salamanca: Sígueme.

Levinas, E. (1994). Dios, la muerte y el tiempo. (Trad. M. L. Rodríguez Tapia). Madrid: Cátedra.

Levinas, E. (1995). Totalidad e infinito. Ensayo sobre la exterioridad. (Trad. D. Guillot). Salamanca: Sígueme.

Levinas, E. (1997). Quelques réflexions sur la philosophie de l'bitlerisme, Paris: Payot et Rivages.

Levinas, E. (2001). Entre nosotros. (Trad. J. L. Pardo). Valencia: Pre-Textos.

Levinas, E. (2002). Être juif. Cahiers d'Études Levinassiennes, 1, 99-106.

Levinas, E. (2004a). La teoría fenomenológica de la intuición. (Trad. T. Checchi). México D. F./ Salamanca: Epidermis/Sígueme.

Levinas, E. (2004b). La renaissance culturelle juive en Europe continentale. Cahiers d'Études Lévinassiennes, (3), 217-226.

Levinas, E. (2005a). Descubriendo la existencia con Husserl y Heidegger. (Trad. M. E. Vázquez). Madrid: Síntesis.

Levinas, E. (2005b). Dificil libertad. (Trad. N. Prados). Buenos Aires: Lilmod.

Levinas, E. (2009). Parole et Silence et autres conférences inèdites au Collège philosophique. Paris: Grasset/IMEC.

Levinas, E. (2011). De la evasión. (Trad. I. Herrera). Madrid: Arena Libros.

Levinas, E., \& Casper, B. (2012). In ostaggio per l'Altro. (Trad. A. Fabris). Pisa: ETS.

Levinas, E. (2013). Escritos inéditos I. (Trad. M. García-Baró). Madrid: Trotta.

Lévy, B. (2005). Levinas et le grec [Hors-série]. Cahiers d'Études Levinassiennes, 195-278.

Rosenzweig, F. (1979). Der Mensch und sein Werk, Gesammelte Scriften (Vol. I). Den Haag: Martinus Nijhoff.

Rosenzweig, F. (1997). La Estrella de la Redención. (Trad. M. García-Baró), Salamanca: Sígueme. 
Scholem, G. (2008). Conceptos básicos del judaísmo. (Trad. J. L. Barbero). Madrid: Trotta.

Úbeda, J. (2014). El prójimo da tiempo. Algunas anotaciones críticas al proyecto filosófico de Levinas. Pensamiento. Revista de Investigación e Información Filosófica, 66(249), 791-808. 